$)$ open access

EDITORES

- Miguel Oliveira Jr. (UFAL)

- René Almeida (UFS)

AVALIADORES

- Renata da Fonte (UNICAP)

- Marlete Sandra (UPF)

SOBRE OS AUTORES

- Fernanda Martins Moreira

Conceptualização, Escrita -

Rascunho Original e Escrita - Análise e Edição.

- Alessandra Del Ré

Conceptualização, Escrita -

Rascunho Original e Escrita - Análise e Edição.

DATAS

- Recebido: 20/08/2021

- Aceito: 05/09/2021

- Publicado: 17/11/2021

\section{COMO CITAR}

MOREIRA, F. M.; DEL RÉ, A. (2021). Um olhar para o processo de

qquisição/aprendizagem de segunda língua em uma escola de idiomas: o papel dos gêneros, dos formatos e da multimodalidade. Cadernos de Linguística, v. 2, n. 4, e566.

\section{UM OLHAR PARA O PROCESSO DE} AQUISIÇÃ̃O/APRENDIZAGEM DE SEGUNDA LÍNGUA EM UMA ESCOLA DE IDIOMAS: O PAPEL DOS GÊNEROS, DOS FORMATOS E DA MULTIMODALIDADE

\section{Fernanda Martins MOREIRA (iD $₫$}

Universidade Estadual Paulista Júlio de Mesquita Filho (UNESP)

\author{
Alessandra Del RÉ (DD $\boldsymbol{X}$ \\ Universidade Estadual Paulista Júlio de Mesquita Filho (UNESP)
}

\section{RESUMO}

O objetivo desta pesquisa é buscar compreender os processos de aquisição/aprendizagem de uma criança que desde 1 ano e 3 meses de idade faz aulas particulares de inglês em uma escola de idiomas. $O$ caso estudado se distingue dos contextos das escolas bilíngues e das escolas de idiomas, entre outros fatores, pelo fato de a interação entre criança-professora ocorrer sempre em inglês, de ser apenas uma criança na sala de aula e de haver uma proposta de interação mais próxima da criança, com atividades lúdicas etc. A partir da perspectiva dialógico-discursiva (BAKHTIN/VOLOSHINOV, 1995; DEL RÉ, DE PAULA, MENDONÇA, 2014) e, ainda, considerando os gêneros do discurso em diálogo com a noção de formatos (BRUNER, 1975, entre outros) e a multimodalidade (CAVALCANTE, 2019), observamos os elementos presentes na interação e na constituição desse sujeito 
entrando na segunda língua (L2). Foram feitas gravações em vídeo na escola de idiomas e os dados foram transcritos no programa CLAN a partir das normas CHAT, ambos fornecidos gratuitamente pela base de dados CHILDES (MACWINNEY, 2000), e foram analisados dados entre 2;10 anos e 3;7 anos. Os resultados mostram elementos presentes na interação professora/criança que servem de apoio para que o processo de aquisição/aprendizagem da segunda língua aconteça. Os gêneros e os formatos alicerçam a entrada na $L 2$, assim como a afetividade, proximidade entre a criança e a professora, a liberdade de escolha, entre outros, promovendo uma interação muito próxima daquela da esfera familiar. Além disso, os elementos multimodais ancoram essa interação, possibilitando que a criança tenha uma atitude responsiva desde o início das interações nesse ambiente escolar.

\section{ABSTRACT}

The objective of this research is to try to understand the acquisition/learning processes of a child who, since 1 year and 3 months old, attends private English lessons in a language school. The case studied differs from the contexts of bilingual schools and language schools, among other factors, including the fact that the interaction between child-teacher always happens in English, that there is only a child in the classroom and there is a proposal of an interaction closer to the child, with games etc. From the dialogicdiscursive perspective (BAKHTIN/VOLOSHINOV, 1995; DEL RÉ, DE PAULA, MENDONÇA, 2014) and also considering the speech genres in dialogue with the notion of formats (BRUNER, 1975, among others) and multimodality (CAVALCANTE, 2019), we observed and discussed the elements in the interaction and the constitution of this subject entering the second language. The data was collected in video in a language school and the transcription was made using CHAT standards of the CLAN program, both provided for free by the CHILDES database (MACWINNEY, 2000). It was analyzed the data between 2;10 years old and 3;7 years old. The results show presence of elements in this interaction that support the second language acquisition/learning process. The genres and formats support the entry into L2 with an interaction very close to the one seen in family sphere, such as affectivity, proximity between the child and the teacher, freedom to 
choose, among others. Furthermore, the multimodal elements anchor this interaction, enabling the child to have a responsive attitude since the beginning of the interaction in this school environment.

PALAVRAS-CHAVE

Interação; aquisição/aprendizagem; gêneros;

formatos; multimodalidade.

\section{KEYWORDS}

Interaction; acquisition/learning; genres; format; multimodality. 


\section{INTRODUÇÃO}

Apresentamos G.1, a criança do nosso estudo de caso, uma menina que vive em uma cidade pequena no interior de São Paulo, filha de pais monolíngues e que começou a frequentar uma escola de idiomas quando estava com 1 ano e 3 meses, ainda em fase da aquisição da sua língua materna (LM), o português brasileiro (PB). A mãe desejava que a criança tivesse contato com o inglês desde o primeiro ano de vida, já que em sua cidade de origem havia diversas escolas bilíngues. Na ausência de uma escola bilíngue na cidade a qual passaram a residir, a mãe de G. procurou o único instituto de idiomas na cidade para sua filha.

Algum tempo depois da entrada dessa criança na escola de idiomas, iniciamos o registro desse percurso, contudo, para fins da pesquisa que aqui relatamos (MOREIRA, no prelo), o recorte selecionado para análise foi o período entre 2;10 anos e 3;7 anos², pois é o momento em que sua produção linguageira começa a aumentar. Assim, investigamos, a partir de um olhar dialógico-discursivo, quais são os elementos em jogo na interação entre uma criança em fase de aquisição/aprendizagem do inglês e sua professora, no contexto de uma escola de idiomas, e como eles contribuem para a construção da relação que a criança vai estabelecer com a outra língua. Em especial, a) observamos como os gêneros e formatos possibilitam que a criança realize a troca de papéis com a professora, bem como assuma a fala da professora, incorporando-a em seu discurso e possibilitando a aquisição/aprendizagem de L2; b) identificamos os elementos multimodais que dão suporte para a aquisição de L2 nesse contexto; c) por último, analisamos a produção da criança na interação com o adulto (professora), tendo como ponto de partida o caráter responsivo dessas produções (gestuais, vocais ou gesto-vocais), relacionando-as com os elementos interacionais que as desencadearam.

Vale dizer que esta pesquisa insere-se em uma pesquisa mais ampla intitulada "Bilinguismo/multilinguismo em contexto familiar e escolar: diferentes panoramas", juntamente com outros trabalhos desenvolvidos pelo Grupo de Estudos em Aquisição da Linguagem (GEALin) da Faculdade de Ciências e Letras de Araraquara (FCL-Ar) e NALíngua-CNPq (BULLIO, 2014, BUENO, 2017, FALASCA, 2017) e que, assim como esses trabalhos, traz um olhar que se volta para o processo e para o sujeito a partir de um ponto de vista dialógicodiscursivo (BAKHTIN/VOLOSHINOV, 1995, DEL RÉ, DE PAULA, MENDONÇA, 2014).

A fim de apresentar as discussões sobre o tema que propomos, iniciamos esse texto explicitando o conceito de bilinguismo que adotamos. Em seguida, apresentamos a nossa fundamentação teórica, com foco na questão dos gêneros do discurso, dos formatos e

1 Usaremos a inicial do nome da criança para preservar sua identidade.

2 A idade da criança será aqui apresentada seguindo este formato: anos; meses. Assim, analisamos os dados de G entre dois anos e dez meses e três anos e sete meses. 
também da produção multimodal; a metodologia, com a explicitação do corpus e os fios condutores da análise; a análise dos dados, trazendo um fragmento como exemplo; e, por fim, trazemos os resultados e os encaminhamentos futuros.

\section{O CONCEITO DE BILINGUISMO}

Devido à crescente demanda de escolas de idiomas e escolas bilíngues para crianças cada vez menores e à valorização do inglês no cenário mundial, faz se necessário investigar como a criança vai lidar com a(s) língua(s) à(s) qual(is) ela vai ser exposta, fora do ambiente familiar, em um contexto onde essa outra língua não é falada no meio social que ela frequenta. Entretanto, por mais que as pessoas procurem "fórmulas mágicas" para se adquirir/aprender uma outra língua, não há "receitas" para se tornar bilíngue, como muitas pessoas buscam. Aliás, a questão se coloca antes mesmo disso, pela definição do que é ser bilíngue ou do que é bilinguismo, visto que há uma variedade imensa de habilidades linguísticas e de contextos que devem ser considerados.

Houwer (2007) apresenta o contexto familiar, em que pais falantes de línguas distintas optam por falar com a criança, cada um usando a sua língua materna. De acordo com a autora, em seus estudos sobre bilinguismo, há situações em que as crianças são expostas a duas línguas em casa, em idade precoce. Nessas situações, podem se tornar falantes das duas línguas ou não. Esse poderia ser considerado o bilíngue "clássico", por assim dizer, pois é a situação mais (re)conhecida, contudo, ainda assim, muitos são os fatores que podem influenciar nesse processo. A autora ressalta que a situação socioeconômica da família não interfere neste resultado, mas a língua que os pais usam na interação com a criança certamente influencia na aquisição de uma segunda língua (L2), assim como a língua mais presente no universo da criança, a língua majoritária, possui mais chances de prevalecer.

François Grosjean (1994) propõe um conceito de bilinguismo baseado na ideia de uso, isto é, aqueles que usam duas ou mais línguas ou dialetos no seu dia a dia. Por exemplo, o imigrante que fala com dificuldade a língua do país que vive, mas que possivelmente não lê nem escreve nessa língua; o intérprete profissional com alto nível de proficiência nas duas línguas; o estrangeiro que interage com os amigos; o cientista que lê e escreve na segunda língua, mas quase nunca fala; pessoas que fazem parte de minorias linguísticas em casa e falam a língua majoritária em outros lugares; a pessoa surda que usa a língua de sinais com os amigos, mas que usa outros tipos de sinais com uma pessoa ouvinte, entre outros exemplos. O que esses sujeitos têm em comum, segundo o autor, é que todos convivem com duas ou mais línguas. Aqueles que não mais usam suas línguas, embora retenham algum conhecimento, são por ele chamados de bilíngues adormecidos.

Em consonância com Grosjean (1994), Houwer (2007) aponta a motivação e a necessidade como fatores importantes para a aquisição de uma segunda língua, sendo 
que, na criança, esses elementos irão aparecer na interação com um interlocutor relevante para ela, como os pais, familiares, cuidadores, professores.

Além dos pontos abordados por esses autores, em nossa pesquisa consideramos ainda o continuum situacional, que possibilita olhar para os modos de uso em que o sujeito transita, entre modo monolíngue e bilíngue a depender da situação. Igualmente relevantes são o papel do interlocutor e da interação, gerando fatores como motivação e necessidade de uso, conforme apresentado por Houwer (2007). São justamente esses elementos a serem observados no presente trabalho, na interação promovida entre criança e professora, que poderiam indicar algum indício de bilinguismo.

Destacamos, também, a escolha por usar aquisição/aprendizagem na nossa pesquisa. Marchezan, Falasca e Bueno (2014) propõem que os processos de aquisição e de aprendizagem não são tão marcados, sendo que o processo de aprendizagem pode gerar aquisição e a aquisição pode direcionar para a aprendizagem. As autoras abordam a impossibilidade de marcar as diferenças entre aprendizagens que acontecem em contexto formal de ensino, como uma escola por exemplo, das que ocorrem fora dela. Da mesma maneira, aqueles que "adquiriram" uma língua em contexto natural podem refletir sistematicamente sobre a língua em alguma fase da vida e os "aprendizes formais" podem conseguir usar a língua de maneia natural sem a necessidade de se pensar nas estruturas linguísticas o tempo do todo.

Sendo assim, devido à ausência de fronteiras explícitas que separam aquisição e aprendizagem, trazemos os processos aquisição/aprendizagem como um contínuo, não fazendo distinção entre eles. Feitas essas considerações, passamos às questões teóricas que servem de base para a análise dos dados que apresentaremos adiante.

\section{FUNDAMENTAÇÃO TEÓRICA: GÊNEROS, FORMATOS E MULTIMODALIDADE}

Partimos de uma perspectiva dialógico-discursiva dentro dos estudos em Aquisição da Linguagem (DEL RÉ, DE PAULA, MENDONÇA, 2014) que considera os gêneros do discurso de Bakhtin (2011) em diálogo com a noção de formatos de Bruner (1985), a fim de compreender a entrada da criança na língua(gem) por meio de jogos e brincadeiras, numa proposta de interação criança/interlocutor. Visto que os trabalhos de Bakhtin e o Círculo não tinham a fala da criança como o foco de seus estudos, consideramos o diálogo desses com as pesquisas de Bruner (1985) e Vygotsky (1985), assim como o fazem os autores que nos servem de base para essa perspectiva, Salazar Orvig (1999) e François (1994, 2015). 
Para Bakhtin/Voloshinov (1995), a língua é vista como uma atividade social constituída por meio da relação estabelecida entre um locutor e um interlocutor na interação verbal, e não apenas como um sistema abstrato de regras como propunha o Estruturalismo. Nessa perspectiva, "[a] língua vive e evolui historicamente na comunicação verbal concreta, não no sistema linguístico abstrato das formas da língua nem no psiquismo individual dos falantes" (BAKHTIN/VOLOSHINOV, 1995, p. 124). Assim, pode-se compreender que a língua reflete e refrata a realidade nas interações entre os sujeitos, produzindo sentidos de acordo com a situação de interação comunicativa.

Dentro desse processo, François (2015) discute que nem toda criança entra na linguagem do mesmo modo, uma vez que possa haver, por exemplo, crianças que falam pouco, mas manifestam uma forte capacidade de compreensão e, portanto, a aquisição não é um processo evidente e igual para todas as crianças. É nesse sentido que o autor propõe não uma teoria da aquisição da língua, mas uma teoria dos "modos de funcionamento da linguagem", pois a aquisição dos aspectos léxico-gramaticais, por si só, não consegue desvendar a relação linguagem-cultura. Sendo assim, os sujeitos, desde o nascimento, estão em constante movimento, pois se constituem na linguagem e são por ela constituídos, tornando-se sujeitos únicos e singulares, mas, ao mesmo tempo, sociais (DEL RÉ, DE PAULA, MENDONÇA, 2014, p. 19):

\footnotetext{
Esse funcionamento não deve ser apenas compreendido a partir de uma perspectiva biológica e psicológica, mas também sociocultural. Pensar linguagem, língua e fala significa refletir tanto sobre a estrutura linguística quanto sobre o uso translinguístico manifestado pelos sujeitos, por meio dela(s). O sujeito não dispensa a estrutura. Ao contrário. Precisa dela para elaborar um dado enunciado linguístico. Todavia, apenas dominar a estrutura não garante nem constitui efetivamente a voz do sujeito.
}

Com base nesse olhar, entendemos a língua como fruto da relação com a sociedade/cultura, constituída por essa relação da criança com o seu outro, por várias formas e por vários caminhos, no processo de aquisição/aprendizagem de L2.

Nesse sentido, destacamos a importância dos gêneros do discurso, como proposto por Bakhtin (2011), pois é por meio deles que a língua, como um fenômeno social, se realiza.

\subsection{GÊNEROS}

A reflexão de Bakhtin (2011, p. 261) afirma que "o emprego da língua se efetua em forma de enunciados (orais e escritos) concretos e únicos". Ele ainda afirma que "cada enunciado é particular e individual, mas que cada campo de utilização da língua elabora seus tipos relativamente estáveis de enunciados, os quais denominamos gêneros do discurso." (BAKHTIN, 2011, p. 262, grifos do autor). Isso significa que falamos sempre por meio de gêneros no interior de uma esfera de atividade. É assim, por meio dos enunciados concretos, que a linguagem penetra na vida e a vida na linguagem. 
A riqueza e a diversidade dos gêneros do discurso são infinitas porque são inesgotáveis as possiblidades da multiforme atividade humana e porque em cada campo dessa atividade é integral o repertório de gêneros do discurso, que cresce e se diferencia à medida que se desenvolve e se complexifica um determinado campo. (BAKHTIN, 2011, p. 262).

Em cada campo da atividade humana, encontramos meios de observar os tipos de enunciados possíveis, ou não, na prática discursiva, delimitados pelos gêneros do discurso. Segundo Bakhtin (2011), a constituição de um gênero do discurso leva em conta três elementos: [...] "o conteúdo temático, o estilo, a construção composicional indissoluvelmente ligados ao todo do enunciado e são igualmente determinados pela especificidade de um determinado campo de comunicação" (p. 262).

A capacidade de organizar os enunciados durante a prática discursiva é uma característica do gênero do discurso e determina quais os tipos de enunciados que integram uma determinada interação, desde as mais simples até as mais complexas. Essa organização permite ao enunciador recorrer às características ou funcionalidades dos gêneros existentes, sem a necessidade de se criar um novo gênero a cada enunciado. Como Bakhtin (2011, p. 283) afirma:

[...] Se os gêneros do discurso não existissem e nós não os dominássemos, se tivéssemos de criá-los pela primeira vez no processo do discurso, de construir livremente e pela primeira cada enunciado, a comunicação discursiva seria quase que impossível.

Apesar do papel regulador dos gêneros, as suas formas diferem substancialmente das formas da língua no sentido normativo, elementos como a entonação expressiva podem mudar o tom a depender da função da situação, da posição social, das relações pessoais de reciprocidade entre os interlocutores. Alguns gêneros possuem um alto grau de estabilidade e coação, como os oficiais; outros nem tanto, a exemplo os gêneros do cotidiano como felicitações ou saudações que vão refletir a individualidade do falante.

Segundo Bakhtin (2011, p. 262), os gêneros são altamente heterogêneos, se mesclam, se misturam, e esse "repertório de gêneros cresce e se diferencia à medida que se desenvolve e se complexifica um determinado campo". É essa heterogeneidade que se observa nesse corpus.

Em nossa pesquisa, o contexto em que G. está adquirindo/aprendendo a L2, quase que ao mesmo tempo em que adquire a LM, como dissemos, nos coloca diante de uma situação bastante singular, já que a L2 se dá em contexto, a priori, escolar, o que pode, aparentemente, nos remeter a uma situação formal da sala de aula. No entanto, em nosso corpus, como veremos adiante, é possível verificar que se trata de uma variação do gênero aula ou ainda de um gênero híbrido. A interação de G. com sua professora promove, pelo que se pode observar, um vínculo afetivo muito próximo daquele presente na esfera familiar, possivelmente pela maneira como a relação professora/criança foi construída, além do fato de ser apenas uma criança e isso promover uma liberdade que 
em uma turma mais numerosa poderia ser menos recorrente. Destacamos, ainda, que se houvesse várias crianças a atenção da professora teria que ser partilhada, o que não ocorre, pois $\mathrm{G}$. tem a total atenção da professora na interação.

Portanto, ainda que a interação entre a professora e a criança se dê em uma esfera escolar (uma escola de idiomas), sugerindo, portanto, a profusão de enunciados do gênero aula, o caso estudado apresenta particularidades que trazem complexidade à essa interação: como dissemos anteriormente, trata-se de uma criança ainda muito pequena, adquirindo sua língua materna, e de uma relação adulto criança permeada por afetividade de forma a aproximá-la do que se observa em uma esfera familiar.

Entendemos que o conceito de gêneros do discurso de Bakhtin (2011) dialoga com a noção de formatos (BRUNER, 1975, 1985, 2007; BRUNER e RATNER, 1978) que propõe a possibilidade da entrada e o desenvolvimento linguístico da criança a partir da interação entre criança e adultos, como apresentaremos no subitem a seguir.

\title{
2.2. FORMATOS
}

Segundo Del Ré (2015), os estudos em aquisição da linguagem buscam explicar, entre outras coisas, como as crianças, por volta dos 3 anos, são capazes de fazer uso produtivo de sua língua; buscam compreender se há um período crítico (idade máxima) em que a criança estaria mais disponivel para o aprendizado, a relação entre a produção e a percepção da linguagem e, ainda - o recorte que interessa a este trabalho - a aquisição/aprendizagem de segunda língua (L2) por crianças em situação formal (escola).

\footnotetext{
Compreender a linguagem da criança e esta como sujeito que enuncia e que, ao enunciar, habita o mundo com voz própria é fundamental para pensar que a linguagem, a língua e a fala não são entidades abstratas, mas enunciados (concretos), ditos por sujeitos que, por meio deles, se constituem e também constituem um modo de ser e habitar o mundo (DEL RÉ, DE PAULA, MENDONÇA, 2014, p. 19).
}

Interessa-nos, igualmente, a perspectiva de Vygotsky (1985), que considera que a fala (egocêntrica) da criança é essencialmente social, ou seja, depende da reação das outras pessoas e tende a se internalizar. Dialogando com essa noção e considerando o papel do outro no processo de aquisição/aprendizagem da criança, seja LM ou L2, como explicamos na introdução, buscaremos compreender o papel desempenhado pelos formatos (BRUNER, 1985) na entrada da criança na linguagem:

\begin{abstract}
Bruner foi um dos pioneiros nos estudos que envolvem a interação entre a criança e seu interlocutor (em geral, a mãe) Para ele, as estruturas de ação e da atenção do homem refletem nas estruturas linguísticas e, à medida que a criança vai dominando gradualmente essas estruturas, a partir do processo de interação do qual o adulto participa, a linguagem vai sendo adquirida (DEL RÉ, 2015, p.23-24)
\end{abstract}

Sendo assim, temos uma criança interagindo com o outro e com o mundo. Para Bruner, neste processo a criança está aprendendo, além do que dizer, como, onde, para 
quem e em que circunstâncias dizer (DEL RÉ, 2015). O conhecimento de mundo e a linguagem se relacionam passando pela interação entre o eu e o outro. As formas rotinizadas observadas pelo pesquisador na interação criança-adulto estruturam de tal maneira essa interação que possibilitam à criança, gradativamente, posicionar-se no diálogo, inclusive alternando papéis e evoluindo até uma consolidação da interação durante a própria atividade de linguagem.

Os jogos da infância também têm um papel importante dentro desse processo (BRUNER e RATNER, 1978; BRUNER, 1985), visto que fornecem uma das primeiras ocasiões para o uso sistemático da linguagem. O adulto, além de proporcionar à criança unidades abstratas da língua, promove, através das atividades linguageiras, um mundo de sentido incluindo o elemento social que estrutura a própria interação. Como exemplos destes formatos podemos citar: jogos de esconder e aparecer, jogos simbólicos, narrativas, saudações, cantigas de ninar, jogos lúdicos, leitura compartilhada, entre outros. O conceito de formatos de Bruner e os conceito de gêneros do discurso de Bakhtin dialogam e aqui consideramos o gênero aula um enunciado maior no qual os formatos estão presentes como atividades rotineiras nas quais a entrada na L2 acontece.

No caso do modelo de aula/interação do nosso estudo de caso, percebemos as escolhas das atividades, ora pela professora ora pela criança, como uma forma de socialização entre elas. A esse respeito, Bruner (1975), em seus estudos, afirma a importância dos formatos para a entrada da criança na linguagem dentro das relações sociais. O autor define formato como "um exemplo simplificado dessa classe de relações. É um microcosmo cercado de regras em que o adulto e a criança fazem coisas para e com o outro." (BRUNER, 1975, p. 76, tradução nossa) ${ }^{3}$.

Contudo, como Bruner (1985) aponta, os formatos crescem e podem se tornar tão complexos e variados quanto necessários, sendo que esse crescimento acontece de muitos modos. Os formatos podem incorporar novos significados ou estratégias que auxiliem na realização dos objetivos, incluindo aqueles simbólicos ou linguísticos; podem mudar o rumo dos objetivos dos dois participantes não apenas em concordância, mas também para a divisão do trabalho e divisão de iniciativas; podem se tornar convencionalizados ou canônicos de um modo que permita que outros dentro de uma comunidade simbólica, como uma comunidade de fala, entrem no formato provisoriamente para aprender suas regras especiais. Além disso, os formatos são receptivos a mudanças, sub-rotinas podem incorporar uma rotina maior, mais longa, como o exemplo do formato de saudação que em uma escala de rotina maior pode envolver outras formas de atenção conjunta.

3 A format is a simplified exemplar of that class of relationships. It is a rule-bound microcosm in which the adult and child do things to with each other. 
Destacamos o papel do adulto na adaptação do discurso adulto para a criança para que ela compreenda gradativamente as distinções conceituais e as funções comunicativas como guias para o uso da linguagem. Sobre isso, Bruner propõe:

[...] essa "adaptação" da interacção do discurso inicial requer cenários familiares e rotinizados, formatos, para que a criança compreenda o que se está a passar, dada a sua capacidade limitada para o processamento de informação. Estas rotinas constituem o que entendo por um sistema de suporte à aquisição da linguagem. (BRUNER, 2007, p. 34).

Entendemos que o desenvolvimento da complexidade do formatos, no contexto dos dados que analisamos, acontece no processo, isto é, a professora oferece um suporte para garantir que a ausência de aptidão (nos referimos à L2 no caso da criança G.) seja amparada por uma intervenção apropriada e, mais tarde, retira o suporte aos poucos, à medida que a criança consegue assumir o papel de sujeito nessa interação e ter maior controle. Os elementos multimodais auxiliam na constituição desse suporte trazido pela professora, assim como também é um recurso de apoio que a criança traz consigo. Sendo assim, abordamos os aspectos teóricos da multimodalidade que dão apoio a nossa pesquisa.

\subsection{MULTIMODALIDADE}

Cavalcante (2019) adentra a perspectiva da multimodalidade no processo de aquisição da linguagem apresentando um histórico de pesquisadores que discutem os gestos como um componente linguístico, sendo assim, compreender gesto e fala em uma matriz gestuo-vocal requer adotar uma perspectiva multimodal para o funcionamento da linguagem. A autora destaca dois autores que, do ponto de vista linguístico, contribuem para as classificações de referência da área: Adam Kendon e David McNeill.

David McNeill (2000), na obra Language and gestures, discute como o fenômeno da gestualidade geralmente passa despercebido, muito embora os gestos sejam onipresentes na linguagem. Observando alguém falando em quase todas as línguas e em quase todas as circunstâncias, encontraremos o que parece ser uma compulsão em movimentar as mãos e os braços juntamente com a fala.

Os gestos que McNeill (2005) trata em sua teoria são os das ocorrências diárias, espontâneas, inconscientes, regularmente acompanhados da fala e que podem ser notados com os movimentos dos dedos, das mãos e dos braços. Segundo o autor, os gestos estão presentes enquanto falamos e, frequentemente, não temos consciência deles. Todavia, ao olhar atentamente ao redor e observar as pessoas conversando em termos informais, é muito provável que vejamos essa ocorrência.

Os estudos de Cavalcante (2019) privilegiam a díade mãe-criança, enquanto McNeill (2000) olha para os gestos dos adultos. É significativo para fins desse trabalho observar como os gestos aparecem na interação professora-criança no nosso estudo 
de caso, nesse processo de aquisição/aprendizagem de L2 por uma criança entre 2;10 anos e 3;7 anos.

Ressaltamos que os estudos sobre gestualidade humana têm crescido, mas somente na última década do século XXI fortalece-se a visão dos gestos enquanto constitutivos da linguagem (KENDON, 1982; MCNEILL, 2000; CAVALCANTE, 2019). Sendo assim, apesar da relevância de se observar os elementos multimodais em seus detalhes e os objetivos deste trabalho, nossas análises, neste momento, não se deterão às especificidades de cada um desses tipos de gestos; interessa-nos, neste momento, entender o modo de funcionamento dos gestos, nesse contexto, por percebê-los como suporte, tanto para a professora quanto para a criança, nessa interação e consequentemente d̀ aquisição/aprendizagem de L2.

Tendo apresentado a nossa fundamentação teórica, explicitaremos a metodologia de pesquisa.

\section{METODOLOGIA}

A coleta de dados foi feita em uma escola de idiomas, em uma situação diferenciada. Em geral, as escolas de idiomas oferecem cursos para crianças pequenas, mas a partir de 3 anos, às vezes menores, em grupo de no máximo 10 alunos, aulas de uma hora, duas vezes por semana e interação entre professora e crianças mesclando inglês e português. Tratase, pois, de um contexto formal de aprendizagem, apesar das atividades pedagógicas terem um caráter lúdico e interativo.

As aulas de G. aconteciam três vezes por semana, com duração de uma hora, em dias e horários definidos e com programação de conteúdo planejada pela professora sob a orientação da coordenação pedagógica da escola. No curso regular, a presença de outras crianças exige da professora um compartilhamento da sua atenção, enquanto que na aula particular, contexto de G., a atenção voltava-se apenas para essa criança, ou seja, trata-se de uma situação que se assemelha muito ao contexto familiar, na interação mãe-criança ou cuidadora-criança/adulto-criança. Nesse contexto, as atividades programadas dão lugar às atividades espontâneas, aquelas que surgem na interação e são acolhidas pela professora.

O primeiro contato de G. com a língua inglesa foi quando ela estava com 1 ano e 3 meses. Desde o início, conforme o histórico da criança na escola, houve um cuidado para que $G$. se familiarizasse com a professora, com a escola e com os funcionários, houve um momento de adaptação para que a criança não estranhasse o contexto. A coordenação da escola propôs um programa de três aulas por semana, recomendando momentos de interação totalmente em inglês no ambiente escolar, tanto com a 
professora quanto com os funcionários da escola ou outros alunos presentes durante o trânsito da criança. A ideia era maximizar o contato que a criança teria com a L2. A proposta foi diferente das demais oferecidas pela escola, uma vez que os cursos existentes são para crianças de cerca de 3 anos de idade e a interação mescla português/inglês, como mencionamos anteriormente.

Desse modo, ficou acordado entre a mãe e a escola que G., por ser ainda muito pequena, deveria se sentir à vontade no ambiente da escola, assim como com as demais pessoas com quem ela interagisse. Da mesma forma, seria necessário estabelecer um vínculo afetivo e uma proximidade com a professora, a fim de que a criança se sentisse acolhida e tranquila para participar das atividades propostas. As aulas começaram com uma leitura, seguidas por atividades lúdicas, introduzindo e praticando a língua inglesa e a criança se adaptou bem.

O contato precoce da criança com a língua inglesa teve início logo nos primeiros anos de vida, nessa escola de idiomas, sendo esse o único espaço de interação em inglês naquele momento. Outra observação é o fato de que ela, enquanto sujeito, escolhia por livre e espontânea vontade interagir em inglês com sua professora e com os demais sujeitos que encontrava, não apenas no contexto escolar semanalmente, mas até mesmo quando ela os encontrava em outras situações, fora da escola.

As atividades previstas para as aulas incluíam a leitura de livros infantis, canções, vídeos, jogos, brincadeiras com desenhos, tintas, massinhas de modelar, brinquedos da escola, cartões (cards), entre outras atividades e recursos presentes no ensino de idiomas que podem e são utilizados para promover a aquisição/aprendizagem da língua inglesa, nesse caso.

Observando a programação das aulas encontramos uma série de atividades rotineiras, entre elas, a leitura de livros, como já mencionamos, que acontecia sempre no início da aula. Inicialmente, o livro era selecionado pela professora de acordo com a idade e com o objetivo da aula, por exemplo uma história sobre os animais viria precedida de atividades com cartões contendo imagens de animais. Contudo, a professora percebeu um interesse maior da criança por alguns livros do que por outros e, por isso, buscava trazer vários livros para que G. escolhesse o que seria lido. Às vezes, a criança pedia para ler mais de um livro, o que era geralmente acolhido pela professora; em outros momentos, a leitura era negociada ou postergada. Os jogos e as brincadeiras estavam presentes e eram retomados a cada aula, criando uma familiaridade com as atividades e possibilitando que a linguagem se desenvolvesse.

Nesse sentido, buscaremos os formatos de Bruner (1985) por entender que, à medida que sustentam essa interação, eles possibilitam que a criança se desenvolva na L2. Os gestos - e toda a multimodalidade que os envolve - têm um papel fundamental, 
considerando que eles estão presentes na linguagem da criança desde o momento em que ela nasce e vão também ajudá-la a construir sua relação com a L2.

Os dados de G. fazem parte de um corpus longitudinal, coletado em uma escola de idiomas no interior de São Paulo com a autorização e orientação do Comitê de Ética ${ }^{4}$. Os dados integram o banco de dados NALingua-CNPq (Núcleo de Estudos em Aquisição da Linguagem).

Todos os participantes interagem com a criança espontaneamente durante as gravações, seja a observadora ou algum funcionário da escola que por ventura esteja próximo. Essa interação é significativa para a pesquisa, considerando que não estamos em um laboratório de línguas, mas em um contexto mais espontâneo.

Os registros foram feitos em vídeos, mensalmente e, quando possível, mais de uma vez ao mês. As sessões gravadas são de aproximadamente uma hora de duração, da chegada até a saída de G. da escola. Todos os dados em vídeo foram analisados para que, então, fossem selecionados os trechos para transcrição, considerando a interação seguida de alguns elementos responsivos, como o olhar, o gesto, o vocal, a participação da criança na atividade, demonstrações de interesse, entre outros.

Os trechos selecionados para análise foram transcritos nas normas CHAT - Codes for the Human Analysis of Transcripts ${ }^{5}$, do programa CLAN - Computerized Language Analysis ${ }^{6}$, fornecido gratuitamente pela base de dados CHILDES - Child Language Data Exchange System ${ }^{7}$, que significa sistema de intercâmbio de dados de linguagem da criança, com uma proposta de compartilhamento de dados (MACWINNEY, 2000).

O corpus da pesquisa é composto, assim, por 10 sessões transcritas, com intervalos regulares, no período entre 2;10 anos e 3;7 anos. Em todas elas, as interações acontecem em inglês - não há enunciados em português por parte da professora/observadora e poucos enunciados em português produzidos pela criança. Para fins deste trabalho, considerando os limites de uma apresentação desta natureza, traremos a análise de um fragmento da última sessão, a fim de demonstrar de que forma os dados foram analisados, a partir da perspectiva teórica adotada.

\subsection{FIOS CONDUTORES DE ANÁLISE}

Como exposto no início do trabalho, queremos desvendar que elementos linguísticodiscursivos e multimodais estão em jogo na interação entre uma criança, em fase de aquisição da linguagem, e sua professora de $L 2$, e qual o papel desses elementos para

\footnotetext{
4 CAAE 18115219.8.0000.5400 (Certificado de Apreciação e Aprovação Ética)

5 Códigos de transcrição para análise humana (Tradução nossa).

6 Análise de língua computadorizada. (Tradução nossa).

7 Disponível em: <https://childes.talkbank.org/>. Acesso em 05 de maio de 2021
} 
esse processo de aquisição, no caso, do inglês, i.e., de que forma esses elementos vão se combinando e, de certa forma, auxiliando a criança, ainda tão nova (entre 2;10 anos e 3;7 anos), a entrar nessa outra língua.

De forma ampla, devemos lembrar, em concordância com Bakhtin (2011), que a criança entra na língua pelo gênero. Assim, não podemos esquecer a especificidade dessa questão aqui neste trabalho, visto que analisamos os dados de uma criança pequena, cujos pais são brasileiros e que, portanto, terá, se não apenas, grande parte de seu contato com essa outra língua por intermédio da professora e desse ambiente escolar (escola de idiomas) que a cerca, poucas horas por semana. Por outro lado, o fato de se tratar de uma criança tão nova faz com que a relação que se estabelece entre ela e a professora, especialmente, não seja apenas de aprendiz/professor, pois há uma afetividade na relação da criança com a professora, algo muito próximo a uma relação familiar.

Assim, em um primeiro momento, discutimos como o gênero aula se apresenta nessa esfera escolar e, considerando os elementos constitutivos do gênero discursivo (tema, a construção composicional e estilo), elaboramos uma tabela e comparamos aspectos mais característicos da esfera escolar e aspectos mais característicos da esfera familiar.

Entendemos que os formatos também constituem esse gênero, inserem-se nele, e a partir das atividades propostas pela professora, nessa esfera escolar, com o objetivo de ensinar inglês, essa interação acontece.

Observando os dados que fazem parte do nosso recorte, de 2;10 anos a 3;7 anos, nos trechos transcritos de acordo com o critério já mencionado anteriormente, encontramos na sequência de atividades uma série de formatos (atividades rotineiras) que se repetem ao longo do percurso da criança nesse ambiente e que são propostos pela professora e, em alguns momentos, solicitados pela criança. Há, ainda, as atividades não planejadas propostas pela criança e que são acolhidas pela professora.

Vale dizer que embora essas atividades sejam propostas frequentemente pela professora, elas não vão aparecer em todas as sessões, já que houve apenas de um ou dois registros mensais.

Eis as atividades presentes nos vídeos:

A. Leitura compartilhada.

B. Clean up: refere-se à organização da sala ao término de cada atividade.

C. Brincadeiras com jogos didáticos: refere-se a atividades utilizando recursos utilizados pela escola de idiomas para o ensino de inglês como língua estrangeira para crianças menores, geralmente a partir dos 3 anos. 
D. Brincadeiras com brinquedos: refere-se às atividades utilizando brinquedos comuns com a finalidade de ensinar vocabulário e estruturas através da interação com o objeto.

E. Atividades escolares: colorir, pintar com tintas, usar massinha de modelar, carimbos, FACES 1-Student's book with áudio CD and stickers ${ }^{8}$ da editora Macmillan Elt, assistir a vídeos infantis, websites interativos etc.

F. Atividades com realia: refere-se aos objetos comuns que são levados para a sala de aula de ensino de língua inglesa com o objetivo ensinar vocabulário e praticar estruturas usando o objeto.

G. Canções: refere-se às canções utilizadas na escola para o ensino de inglês para crianças - são canções de saudação, canções de despedida, canções com histórias, canções de ninar e canções infantis, em geral.

Dentro desses formatos, encontramos:

1. Os tipos de intervenções feitas pela professora na sua proposta de interação:

a) Perguntas fechadas (aquelas em que se espera sim ou não como resposta);

Can you comb my hair? (Você pode pentear meu cabelo?)

Is it difficult? (É difícil?)

b) Perguntas com Wh-questions (What, where, when, who etc);

What color is your toothbrush? (Qual a cor da sua escova de dente?)

Where are you going with this bag? (Onde você está indo com esta bolsa?)

c) Comandos;

Don't do this! (Não faça isso!)

Be careful. (Tenha cuidado.)

d) Proposição em forma de sugestão.

Let's go bowling! (Vamos jogar boliche!)

Let's clean up! (Vamos organizar a sala!)

8 O livro didático não é utilizado frequentemente com G, ela não se interessa muito pelas atividades. Entretanto, é o livro usado regularmente com as turmas de crianças pequenas que estudam na escola. 
2. A produção responsiva por parte de G. (responsividade), que pode ser:

a) Gestual;

b) Gesto-vocal;

c) Vocal;

d) Ação (consideramos também resposta quando a criança, apesar de não responder com gesto, nem com vocalização, age atendendo à solicitação da professora).

Considerando os gestos como um elemento constitutivo da linguagem (KENDON, 1982; MCNEILL, 2000; CAVALCANTE, 2019), percebemos que, desde a primeira sessão, eles parecem contribuir para uma atitude responsiva por parte da criança, visto que de acordo com Bakhtin (2011, p. 271) "toda compreensão é prenhe de resposta", sendo que ela (a criança) não tem domínio dessa segunda língua ainda, ou seja, ela lança mão de elementos gestuais para interagir com a professora, que, por sua vez, parece tentar se ajustar à criança. Diante disso, analisaremos como os elementos multimodais dão apoio e suporte ao uso da L2 por G.

\section{ANÁLISE DOS DADOS}

Apresentamos os elementos que constituem o gênero aula e a variação que esse gênero sofre na interação de G. com a professora. Para isso, há uma relevância em se reconhecer os seus elementos constitutivos, já que é por meio dele que o processo de aquisição/aprendizagem de L2 acontece.

Considerando os elementos que constituem um gênero do discurso, trazemos no quadro a seguir alguns aspectos observados em nossos dados, separando-os de acordo com o que é mais característico da esfera escolar e o que é mais característico da esfera do cotidiano familiar, a fim de mostrar as nuances que possibilitam o hibridismo observado em nossos dados.

\begin{tabular}{|c|c|}
\hline $\begin{array}{c}\text { Aspectos mais característicos da esfera } \\
\text { escolar }\end{array}$ & $\begin{array}{c}\text { Aspectos mais característicos da } \\
\text { esfera familiar }\end{array}$ \\
\hline O ensino de inglês & $\begin{array}{c}\text { Liberdade de escolha das } \\
\text { brincadeiras/atividades propostas }\end{array}$ \\
$\begin{array}{c}\text { Sequência de atividades propostas } \\
\text { (roteiro de aula) } \\
\text { início e término da aula }\end{array}$ & Atividades espontâneas/não planejadas \\
\hline
\end{tabular}




\begin{tabular}{|c|c|}
\hline Tom didático & $\begin{array}{c}\text { Interação de apenas uma criança com } \\
\text { adulto (muito parecido com a relação } \\
\text { mãe-criança) }\end{array}$ \\
\hline Checagem de aprendizado & $\begin{array}{c}\text { Proximidade entre os interlocutores } \\
\text { Marcas de afetividade }\end{array}$ \\
\hline
\end{tabular}

Quadro 1. Aspectos característicos da interação em esfera escolar e em esfera familiar observados nos dados de $G$.

Fonte: elaborado pelas autoras.

Apesar de ser possível pensar no gênero aula como uma forma relativamente estabilizada, o que se observa nos dados é algo bastante "instável", na medida em que o tipo de interação com a professora mescla atividades que são pensadas previamente para a situação de sala de aula, por um lado, mas que, por outro lado, têm mais um caráter lúdico do que de ensino/aprendizagem. Outro elemento importante é o fato de G. propor atividades, recusar-se a participar de algumas propostas da professora, passar a vez, negociar, entre outros posicionamentos que demonstram sua participação ativa nessa interação. Além disso, os laços criados entre G. e a professora se assemelham a tipos de interação familiares: o tipo de linguagem dirigida a ela, a proximidade física com a criança etc. Isso mostra a flexibilidade do gênero, permitindo que outros formatos o componham. É essa natureza dialógica e dialética do gênero que permite que o sujeito se constitua como um sujeito singular.

Uma vez que a heterogeneidade dos gêneros do discurso apontada por Bakhtin (2011) não pode ser minimizada, nem a dificuldade que surge em definir a natureza geral do enunciado, propomos pensar o gênero aula com uma certa estabilidade, como as apresentadas, e apesar de outros elementos estarem imbricados, não chegam a desconfigurar o gênero, pois o objetivo dessa interação é o ensino da língua inglesa em um ambiente escolar, lugar em que ocorre essa interação.

Na composição estrutural, temos o intervalo de tempo de uma hora, uma sequência de atividades com a finalidade de ensinar e praticar o inglês, e a participação da aluna respondendo a essa interação, sempre interpelada pela professora. O caráter lúdico da proposta didática não altera seu objetivo. A liberdade de escolha entre as atividades, em uma aula regular, não é tão frequente; conquanto nem sempre os alunos/as acolham a proposta do educador, sempre se espera que eles façam o que está sendo solicitado. A negociação é um elemento mais comum na esfera familiar com a mãe/pai/adulto, e muito embora ela possa acontecer em qualquer aula, dentro da escola de idiomas ou em outra escola, percebemos nessa interação um outro nível, sendo muito mais aberta e muito mais flexível. Nesse espaço, percebemos a criança não só recusando, mas também 
propondo outras brincadeiras/atividades. Essa liberdade acontece porque, em se tratando de aulas particulares, a criança tem total atenção e consegue ser respondida e atendida nas suas vontades, sem que isso descaracterize a proposta de ensino.

Considerando o estilo como elemento constitutivo do gênero do discurso, seja oral ou escrito, primário ou secundário, ele irá refletir a individualidade dos falantes em maior ou menor grau. Para Bakhtin (2011), os gêneros que exigem uma maior padronização da forma são aqueles em que as condições estão menos propícias para a manifestação da individualidade, a depender da função da comunicação discursiva exercida em cada campo. A partir dessa perspectiva bakhtiniana, o gênero aula possui um tom didático, "professoral", evidenciando o papel de ensinar nos enunciados declarativos, ora ensinando um determinado vocábulo, ora dando instruções de como fazer, brincar, responder etc. É a professora quem delimita as ações permitidas naquele espaço e, por isso, encontramos no seu discurso a autorização para o que pode ou não ser feito. Ainda como característica desse estilo está presente a verificação da compreensão e do aprendizado através da interação responsiva esperada.

Entretanto, no nosso estudo de caso, há uma variação desse estilo, já que o tom didático/professoral muitas vezes oscila. A professora permite a alternância dos papéis e, em outros momentos, ela se coloca na mesma posição da criança na troca de ideias, de gostos, de preferências, em uma posição quase horizontal, muito próxima da criança.

Por último, destacamos que é comum, na educação infantil, uma maior afetividade entre criança e professoras. Conforme os anos escolares vão se desenrolando, essa marca de afetividade pode - ou não - diminuir. Essas marcas de afetividades são mais ou menos evidentes a depender do estilo individual dos falantes e estão presentes na esfera familiar também. Percebe-se, na interação entre G. e a professora, o abraço, os beijos, as brincadeiras carinhosas como alguém do meio familiar e até enunciados em que a criança diz gostar da professora e vice-versa

A partir dessa reflexão, percebemos que, embora ocorra uma variação do gênero aula (tornando-o menos convencional), não acontece uma desconfiguração do gênero.

Para dar uma amostra do que propusemos até o momento, selecionamos, para este trabalho, uma cena (sessão 10 - G. 3;7 anos) em que é possivel observar uma interação espontânea em que aparecem muito dos elementos mencionados anteriormente.

As canções estão presentes em todas as aulas. Elas aparecem (e se repetem) no início da aula com canções de saudação, no final com canções de despedida e às vezes no meio da aula, trazendo alguma canção selecionada previamente pela professora, geralmente tocada no computador com projeção na TV. Esse formato é muitas vezes apresentado por meio de vídeos, a professora também canta em muitos momentos, mas no fragmento que vamos apresentar não há vídeos nem a voz da professora (apenas os gestos), pois é a criança que traz a canção. 
Nessa cena, a professora havia trazido os animais de pelúcia para a aula, G. segura o "tubarão" nos braços enquanto o acaricia. A professora pede para que a criança cante a canção "the five little monkeys"9 para o tubarão, e a criança canta.

\section{Fragmento - G. 3;7 anos}

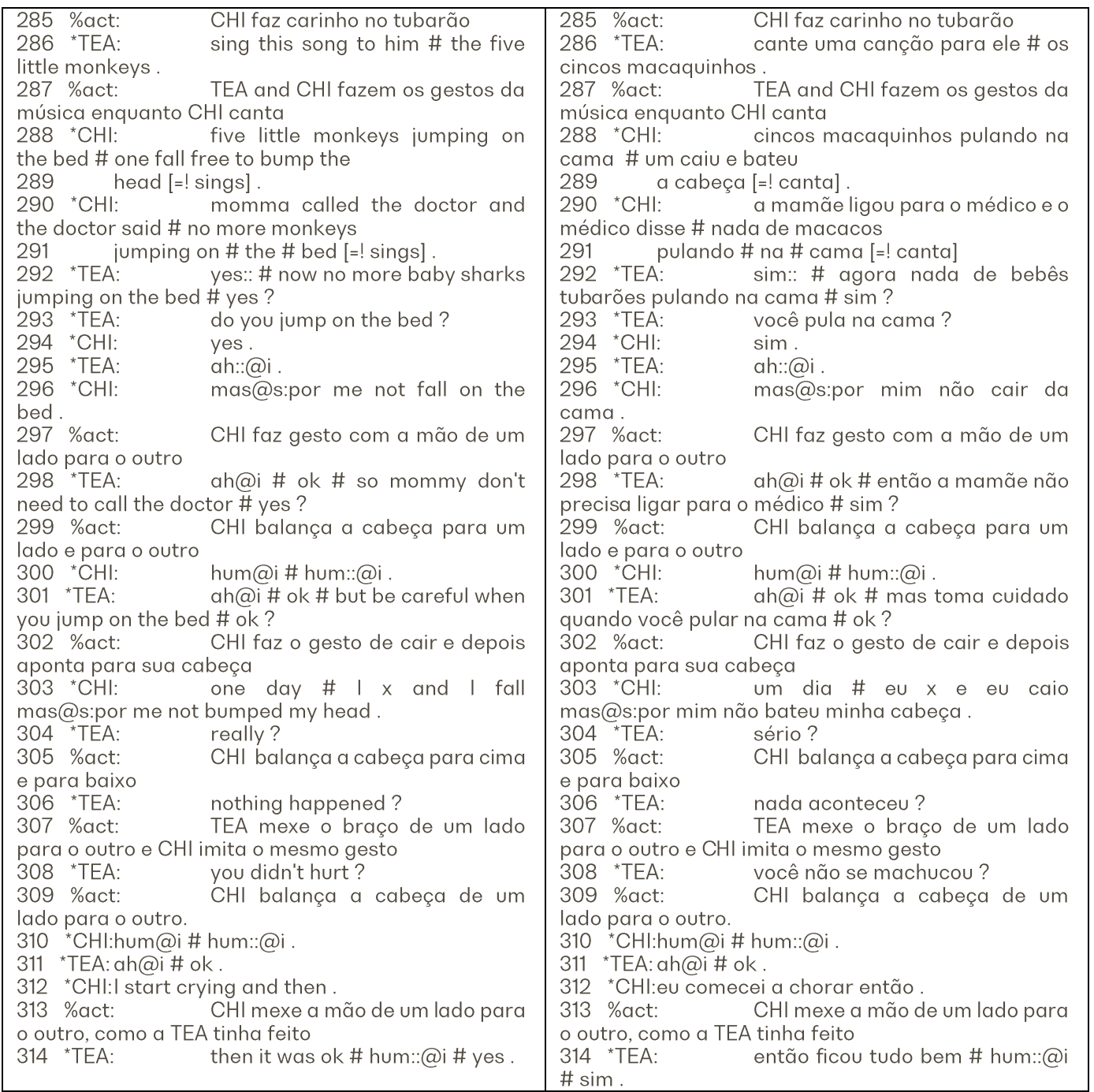

A criança canta a canção ao mesmo tempo em que faz os gestos, a professora também faz os gestos da canção, as duas estão quase em sincronia, mas a professora não vocaliza. Os elementos multimodais utilizados estrategicamente pela professora apoiam a criança na sua cantoria em L2. O dedo indicador apontado para baixo, subindo 
e descendo como se fosse um macaquinho pulando; a mão, formando um telefone, levada ao ouvido; o dedo indicador de um lado para o outro indicando "não faça isso"; esses são alguns exemplos dos gestos que aparecem na cena.

Percebemos que o formato canção contribui para $\circ$ processo de aquisição/aprendizagem de G. quando os elementos da canção são deslocados para a vida real e trazidos na sua narrativa pessoal. A professora pergunta se ela pula na cama, ela responde que sim com uma resposta vocal, mas acrescenta que não caiu da cama, uma resposta gesto-vocal, pois mexe a mão fazendo o gesto emblemático de não. A professora confirma, então, se não se machucou, o que a criança responde com uma resposta gesto-vocal, balança a cabeça e diz "hum hum" (310), que é interpretado como não. Diante do conselho da professora "Be careful when you jump on the bed, ok?", a criança parece lembrar de um episódio e narra que um dia ela caiu, mas não bateu a cabeça. A professora faz cara de surpresa e tenta confirmar a informação, perguntando "really?". A criança dá uma resposta gestual balançando a cabeça para cima e para baixo, o que é interpretado pela professora como sim. A professora insiste e faz uma pergunta fechada seguida de um gesto: levanta a mão da esquerda para a direita, querendo confirmar se nada aconteceu $(306,308)$, e a criança dá uma resposta gestual indicando que não com a cabeça. Nesse momento, a criança acrescenta que começou a chorar "I start crying and then" (312), uma resposta vocal, entretanto, percebemos nesse enunciado um elemento novo: como consequência da queda temos o choro. A criança está mais uma vez se posicionando subjetivamente nesse discurso.

Observamos que nessa interação a criança está apoiada nos elementos multimodais que a auxiliam a fazer uso da L2 que ela está adquirindo/aprendendo, fazendo o deslocamento do formato inicial (a canção), modificando-o completamente e, com autonomia, participando genuinamente do diálogo com o seu interlocutor. Ela traz uma experiência da sua LM para a L2 nesse espaço de interação em que ela está inserida.

Nesse sentido, os formatos propostos pela professora têm o papel de iniciar a criança nessa outra língua e, à medida que se complexificam, como no fragmento trazido, promovem o processo de aquisição/aprendizagem de L2, também constituindo esse gênero (híbrido).

Uma observação sobre a responsividade precisa ser trazida nesse momento. Entendemos, com base nas reflexões de Bakhtin e do Círculo, que toda manifestação da criança é um ato responsivo, isto é, mesmo quando ela ignora a intervenção da professora temos uma resposta (não é o exemplo da cena). Entretanto, temos uma atitude responsiva engajada quando a criança se envolve mais na atividade proposta, construindo sentidos, interagindo com os recursos que possui, sejam eles gestuais, vocais em LM ou L2. E, mais uma vez, o jogo simbólico tem um papel singular no envolvimento da 
criança com a atividade, pois a professora o alimenta e o fortalece, e isso parece motivar a criança a participar.

\section{RESULTADOS E ENCAMINHAMENTOS FUTUROS}

A pesquisa apresentada buscou compreender como os elementos presentes na interação entre criança e professora, em um contexto de ensino de inglês, contribuem para o processo de aquisição/aprendizagem dessa outra língua. Os dados observados, oriundos de um contexto escolar particular, permitem que analisemos o gênero aula, com as suas alterações, mesclando marcas próprias dessa esfera (a escolar) com marcas da esfera familiar. A heterogeneidade dos gêneros, segundo Bakhtin (2011), permite que o gênero se transforme e se modifique à medida que se desenvolve. Isto é relevante, pois percebemos esse gênero híbrido como um dos elementos na interação que possibilita que o processo de aquisição/aprendizagem de L2 aconteça.

Buscando o diálogo entre Bakhtin (2011) e Bruner (1975, 1985), entendemos que os formatos fazem parte da constituição desse gênero. As atividades rotineiras permitem à criança adquirir/aprender a L2, já que à medida que as propostas da professora se repetem, ela traz oportunidades de a criança compreender a situação, a proposta e interagir com a professora. Retomamos a definição de formato, como proposto por Bruner (1975, p. 76), "microcosmo cercado de regras em que adultos e crianças fazem coisas para e com o outro", sendo assim, encontramos a professora e a criança fazendo coisas juntas o tempo todo, a professora se inclui nessa interação com uma linguagem mais propositiva do que diretiva. Não que o papel do professor não esteja presente, mas esse papel se torna um tanto diferente nessa interação, como percebemos na pesquisa com um todo. A afetividade, a proximidade entre professora e aluna, a liberdade de escolha, a recusa, a liberdade de propor a atividade ou um novo rumo ao diálogo são exemplos percebidos nessa interação que a torna bem singular e, nesse contexto, esses elementos amparam o processo de aquisição/aprendizagem de L2.

Ao observar os formatos presentes na interação criança/professora, encontramos os elementos supracitados. A professora, ajustando-se à resposta da criança que nem sempre tem interesse pela proposta de aula, cria condições para desenvolver um padrão de interação no qual a criança possui uma atitude responsiva, utilizando os recursos de que dispõe para fazer as atividades (brincar, jogar, montar etc.) e responder a partir dos gestos e da L2.

De acordo com a perspectiva dialógico-discursiva bakhtiniana, todo enunciado evoca uma atitude responsiva do outro, formando um elo na cadeia discursiva. Nesse sentido, o discurso da professora ganha voz no outro, alternando os papéis e permitindo que a L2 
seja usada. Assim, percebemos como a criança se apropria da L2 para se posicionar como sujeito na interação.

Observamos como a multimodalidade e, em particular, como os gestos presentes na interação, servem de apoio para G., sendo em um primeiro momento interpretados pela professora e nomeados por ela. Em um segundo momento, por meio das atividades rotineiras, acontece uma apropriação de um repertório linguístico que permite à criança o uso da L2, ao ponto de permitir uma mudança qualitativa no posicionamento do sujeito nesse diálogo, fazendo suas propostas e manifestando suas vontades. Essa atitude responsiva da criança, em alguns momentos, pode vir com uma proposição da própria criança, que passa a não apenas responder, mas também assumir outro papel na interação.

Compreendendo os gestos como constitutivos da linguagem (KENDON, 1982; MCNEILL, 2000; CAVALCANTE, 2019), entendemos que a criança desde o nascimento já interage por meios dos gestos. Nesse espaço de interação em L2, em que o uso da LM não é encorajado, os gestos ancoram essa interação possibilitando à professora se fazer entender e à criança ter uma atitude responsiva às intervenções da professora, portanto, a multimodalidade é um dos elementos que colabora no processo de aquisição/aprendizagem de L2. Entendemos que os gestos, que têm um papel essencial nos primeiros anos da criança, desempenham um papel importante também nesse contexto de escola de idiomas

Há uma certa singularidade no contexto apresentado e vários elementos que contribuem para que o processo de aquisição/aprendizagem de L2 dessa criança aconteça. Ressaltamos que há elementos outros, intrínsecos, que não podem ser simplesmente replicados com outra criança a fim de atingir o mesmo resultado, pois os sujeitos são únicos, como únicos também são os enunciados e as relações que eles estabelecem entre si. Entretanto, é possível observar os elementos presentes nesse contexto e que contribuem para o processo de aquisição/aprendizagem dessa língua outra e discutir como eles podem aparecer na prática pedagógica, auxiliando a melhorar o ensino de línguas, sendo eles: a entrada na língua através dos gêneros e dos formatos, os ajustamentos que a professora realiza para que a criança tenha uma atitude responsiva, os recursos multimodais em que a criança e a professora se apoiam para promover a interação, o foco de atenção conjunta, a afetividade, a liberdade de escolha, entre outros exemplos encontrado na análise dos dados.

Por fim, acreditamos que há muitas questões a serem investigadas no futuro a partir desse cenário, dentro da perspectiva em que nos encontramos, na busca por compreender melhor a constituição do sujeito bilíngue ou aprendiz e o seu processo de aquisição/aprendizagem dessa outra língua, possibilitando novas descobertas e enriquecendo as pesquisas na área da Aquisição da Linguagem. 


\section{REFERÊNCIAS}

BAKHTIN, Mikhail. Estética da criação verbal. Trad. Paulo Bezerra. 6 ed. São Paulo: Martins Fontes, 2011.

BAKHTIN, Mikhail.; VOLOSHINOV, Valentin. Marxismo e filosofia da linguagem. Problemas fundamentais do método sociológico na ciência da linguagem. Trad. Michel Lahud e Yara Frateschi Vieira. 7. ed. São Paulo: Hucitec, 1995.

BRUNER, Jerome. From communication to language: a psychological perspective. Cognition, n.3, p. 255-287, 1975.

The Role of Interaction Formats in Language Acquisition. In FORGAS, Joseph Paul (Ed.), Language and Social Situations, Springer-Verlag, New York, 1985

2007

Como as crianças aprendem a falar. Tradução de Joana Chaves. Lisboa: Horizontes Pedagógicos,

BRUNER, Jerome; RATNER, Nancy. Games, social exchange and the acquisition of language. Journal of Child Language, v.5, n³, p. 391-40I, 1978.

BUENO, Rafaela Giacomini. O uso e a omissão do sujeito pronominal de $1^{\text {a }}$ e $2^{a}$ pessoas em português brasileiro e em espanhol: subjetividade, jogo e gênero pedagógico. Tese (Doutorado em Linguística e Língua Portuguesa) Unesp - Araraquara, 2017.

BULLIO, Paula Cristina. Referência e code-switching: traços de singularidade na linguagem de uma criança bilíngue. Tese (Doutorado em Linguística e Língua Portuguesa) - Unesp - Araraquara, 2014

CAVALCANTE, Marianne Carvalho Bezerra. Perspectiva multimodal da aquisição da linguagem. In: MOTA, Mailce Borges; NAME, Cristina (Orgs.). Interface linguagem e cognição: contribuições da Psicolinguística. Florianópolis: Tubarão Copiart, 2019.

DEL RÉ, Alessandra. A pesquisa em Aquisição da Linguagem: teoria e pratica. In: DEL RÉ, Alessandra. (Org.) Aquisição da linguagem: uma abordagem psicolinguística. São Paulo: Contexto, 2015. p. 13- 40.

DEL RÉ, Alessandra; DE PAULA, Luciane.; MENDONÇA, Marina Célia. Aquisição da linguagem e estudos bakhtinianos do discurso. In: DEL RE, Alessandra; DE PAULA, Luciane; MENDONÇA, Marina Célia (Orgs.). Explorando o discurso da criança. 1.ed. São Paulo: Contexto, 2014. p. 17-30.

FALASCA, Patrícia. "Eu disse tudo isso em alemão, mas em português penso totalmente diferente": identidade e argumentação na sala de aula de língua estrangeira. Tese (Doutorado em Linguística e Língua Portuguesa) Unesp - Araraquara, 2017.

FRANÇOIS, Frédéric. Continuité et mouvements discursifs dans des dialogues. Rééducation orthophonique, v. 32, n. 179 , p. $211-241,1994$.

O que nos indica a "linguagem da criança": algumas considerações sobre a "linguagem". Trad. Guacira Marcondes Machado Leite. In DEL RÉ, Alessandra (Org.). Aquisição da Linguagem: uma abordagem psicolinguística. São Paulo: Contexto, 2015. p. 183-200.

GROSJEAN, François. Individual bilingualism. The Encyclopedia of Language and Linguistics. Oxford: Pergamon Press, 1994

HOUWER, Annick De. Parental language input patterns and children's bilingual use. Applied Psycholinguistics, $v$. 28, n. 3, p. 411-424, 2007

KENDON, Adam. The study of gesture: some remarks on its history. Recherches Sémiotiques/Semiotic Inquiry 2: 45-62, 1982.

MCNEILL, David. Introduction. In: MCNEILL, David (Ed.). Language and gesture. Cambridge: Cambridge University Press, 2000. p. 1-10. 
MACWHINNEY, Brian. The CHILDES Project. Tolls for Analyzing Talk. Third Edition. Mahwah, New Jersey: Lawrence Erlbaun Associates, 2000.

MARCHEZAN, Renata Coelho; FALASCA, Patrícia; BUENO, Rafaela Giacomini. Aquisição/Aprendizagem de língua estrangeira e as contribuições bakhtinianas. In: DEL RÉ, Alessandra; DE PAULA, Luciane; MENDONÇA, Marina Célia (Orgs.). A linguagem da criança: um olhar bakhtiniano. 1ed. São Paulo: Editora Contexto, 2014. p. 95-111.

MOREIRA, Fernanda Martins. O papel da interação no processo de aquisição/aprendizagem de segunda língua: um estudo de caso em uma escola de idiomas. Dissertação (Mestrado em Linguística e Língua Portuguesa) Unesp - Araraquara, no prelo.

SALAZAR-ORVIG, Anne. Les mouvements du discours: style, réference et dialogue dans des entretiens cliniques. Paris: L'Harmattan, 1999.

VYGOTSKY, Lev Semyonovich. Pensamento e Linguagem. Trad. Nelson Jahr Garcia, Ed. Ridendo Castigat Mores, 1985. E-book. Disponível em: <http://www.ebooksbrasil.org/adobeebook/vigo.pdf>. Acesso em 05 de janeiro de 2021. 